\title{
Azomesogens with 1,2,4-trisubstituted benzene moiety ${ }^{\dagger}$
}

\author{
R A VORA and A K PRAJAPATI* \\ Applied Chemistry Department, Faculty of Technology and Engineering, M.S. University of Baroda, \\ Vadodara 390 001, India
}

MS received 26 June 2001; revised 14 June 2002

\begin{abstract}
New mesogenic homologous series having an azo central linkage was synthesized by fixing a rigid 4-methyl phenyl azo group to resorcinol moiety. The terminal and lateral phenolic -OH groups were esterified, one by one, with 4-n-alkoxybenzoyl and acetyl group, respectively. All the twelve homologues synthesized exhibit mesomorphism. The methoxy to $n$-decyloxy and $n$-hexadecyloxy derivatives exhibit monotropic nematic mesophase whereas, $n$-dodecyloxy and $n$-tetradecyloxy derivatives exhibit enantiotropic nematic mesophase. The mesogenic properties of the present series was compared with those of other structurally related mesogenic series.
\end{abstract}

Keywords. 1,2,4-Trisubstituted benzene; lateral acetyloxy group; nematic mesophase.

\section{Introduction}

Until 1983 it was generally accepted that lateral substituents diminish the mesogenic property of a compound, the extent of the effect depending on their size. As found by Weissflog and Demus (1983, 1984), surprisingly, compounds with large flexible lateral substituents exhibit liquid crystalline phases. They also reported (Weissflog and Demus 1985) compounds containing two long chain lateral substituents that are nematic. Cox et al (1984) synthesized nematogens in which lateral phenyl group is attached without a spacer. Gallardo and Muller (1984), Weissflog and Demus (1988) and Weissflog et al (1986, 1990) also reported mesogens with lateral aromatic substituents. Subsequently number of homologous series with trisubstituted benzene nucleus have appeared in the literature (Baumeister et al 1990; Diele et al 1991; Berdague et al 1995; Weissflog et al 1996; Weissflog and Jacobi 1997; Perez et al 1997). Recently, we reported (Vora et al 2001) four mesogenic homologous series containing three rings in the main core and substituted by a lateral aromatic branch or hydroxy group on the central benzene nucleus. The mesogenic homologous series with lateral hydroxy group exhibited nematic mesomorphism whereas homologous series with lateral aromatic branch exhibited smectogenic tendencies. In the present work, we have introduced lateral acetyloxy group in order to study the effect of such a group on the mesomorphic properties and transition temperatures as this group will lower the transition temperatures. Further, the effect of lateral

\footnotetext{
*Author for correspondence

${ }^{\dagger}$ Paper presented at the 5th National Seminar on Liquid Crystals, University of Jammu, Jammu, December 1997.
}

acetyloxy group has not been studied extensively and this prompted us to carry out the present work.

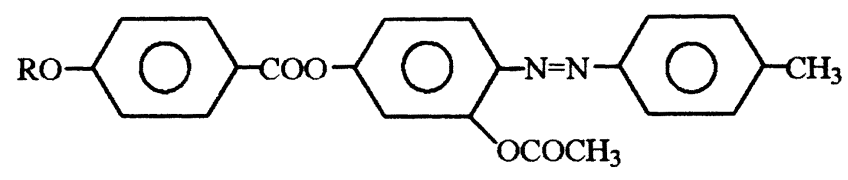

Series I.

\section{Experimental}

\subsection{Characterization}

Microanalysis of the compounds were performed on a Coleman carbon-hydrogen analyser, and IR spectra were recorded on Shimadzu IR-408 using $\mathrm{KBr}$ pellets. ${ }^{1} \mathrm{H}$ NMR spectra were recorded on a Perkin-Elmer R-32 spectrometer using TMS as a standard. The calorimetric studies were carried out on a Mettler TA 4000 DSC apparatus by adopting a scanning rate of $5^{\circ} \mathrm{C} / \mathrm{min}$. Liquid crystalline properties were investigated on a Leitz Labourlux 12 POL microscope provided with a heating stage.

\subsection{Synthesis}

4-Hydroxybenzoic acid, the appropriate $n$-alkylhalides $(\mathrm{BDH})$, resorcinol, $p$-toluidine and thionyl chloride (Sisco Chem.) were used as received. All the solvents were dried and distilled prior to use. The compounds of the new series I were prepared following the pathway shown in scheme 1 . 


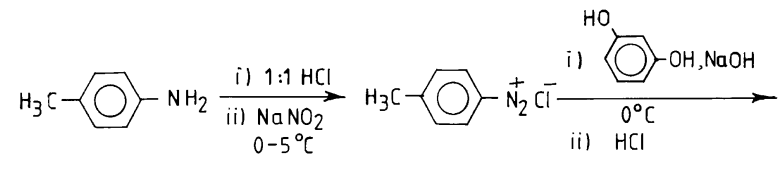

$$
\begin{aligned}
& \mathrm{H}_{3} \mathrm{C}-\mathrm{O}-\mathrm{N}=\mathrm{N}-\mathrm{OH} \\
& \text { [A] } \\
& \text { HO- }-\underset{\mathrm{EHOH}}{\mathrm{COOH}} \frac{\mathrm{RBr}}{\mathrm{KOH}} \mathrm{RO}-\mathrm{O}-\mathrm{COOH} \frac{\mathrm{SOCl}_{2}}{(\text { Excess })} \mathrm{RO}-\mathrm{O}-\mathrm{COCl}
\end{aligned}
$$

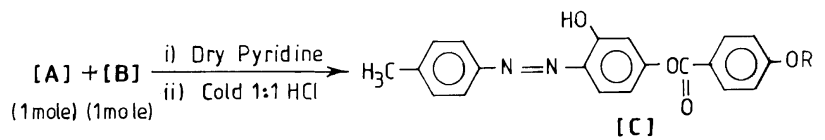

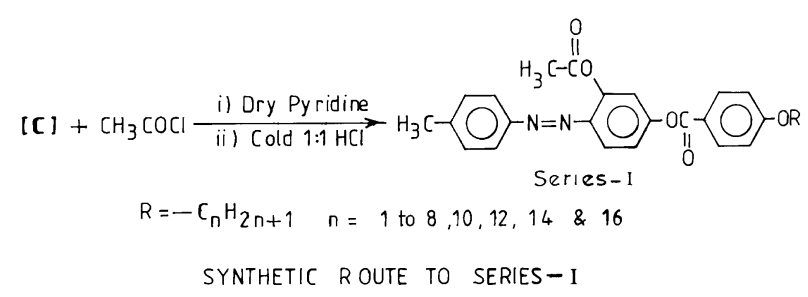

Scheme 1.

2.2a 4-Methyl 2',4'-dihydroxy azobenzene $(A)$ : This compound was synthesized by using conventional method of diazotization and coupling (Vogel 1989).

2.2b 4-n-Alkoxybenzoyl chloride (B) and 4-methyl 2'hydroxy 4'-(4"-n-alkoxybenzoyloxy) azobenzenes $(C)$ : The synthesis of these compounds is described elsewhere (Vora et al 2001).

2.2c General procedure for synthesis of series I compounds: Compound C (10 mmol) was dissolved in dry pyridine $(15 \mathrm{ml})$ and added slowly into acetyl chloride
(10 mmol) in dry pyridine $(15 \mathrm{ml})$ below $15^{\circ} \mathrm{C}$. The mixture was then heated on a water bath for $1 \mathrm{~h}$ and was allowed to stand overnight at room temperature. It was acidified with cold $1: 1$ aqueous hydrochloric acid. The solid was separated, dried and triturated by stirring for 30 min with $10 \%$ aqueous sodium hydroxide solution and washed with water. The insoluble product was thus separated from the reactants. Finally all the products were crystallized from alcohol till constant transition temperatures were obtained. The elemental analysis (table 1) of all the compounds was found to be satisfactory. IR and ${ }^{1} \mathrm{H}$ NMR spectral data of $n$-butyloxy derivative of series I are given below.

IR $(\mathrm{KBr}) \operatorname{spectra}\left(v_{\max }, \mathrm{cm}^{-1}\right): 2950,1760,1720$ (-COO-), 1605 (-N=N-), 1505, 1465, 1365, 1250, 1230, 1200, 1165, $835,755$.

${ }^{1} \mathrm{H}$ NMR spectra (Solvent $\left.\mathrm{CDCl}_{3}, 60 \mathrm{MHz}\right): \delta \quad 0.9$ $\left(t, 3 \mathrm{H},-\mathrm{CH}_{3}\right), 1 \cdot 4-1 \cdot 7\left(m, 4 \mathrm{H}, 2 x-\mathrm{CH}_{2}-\right), 2 \cdot 3(s, 3 \mathrm{H}$, $\left.-\mathrm{PhCH}_{3}\right), 2 \cdot 4\left(s, 3 \mathrm{H},-\mathrm{OCOCH}_{3}\right), 4.0\left(t, 2 \mathrm{H},-\mathrm{OCH}_{2}-\right)$, $6 \cdot 8-7 \cdot 2\left(m, 5 \mathrm{H}\right.$ at $\mathrm{C}-3^{\prime}, \mathrm{C}-5^{\prime}, \mathrm{C}-3, \mathrm{C}-5$ and $\left.\mathrm{C}-6^{\prime}\right), 7 \cdot 6-8 \cdot 0$ $\left(m, 4 \mathrm{H}\right.$ at $\mathrm{C}-3^{\prime \prime}, \mathrm{C}-5^{\prime \prime}, \mathrm{C}-2$ and $\left.\mathrm{C}-6\right), 8 \cdot 0-8 \cdot 2(d, 9 \mathrm{~Hz}$, $2 \mathrm{H}$ at $\mathrm{C}-2^{\prime \prime}$ and $\left.\mathrm{C}-6^{\prime \prime}\right)$.

\section{Results and discussion}

The transition temperatures for compounds of series I are recorded in table 2. Calorimetry is a valuable method for the detection of phase transitions. It yields quantitative results, therefore, we may draw conclusions concerning the nature of the phases which occur during the transitions. In the present study, enthalpies of $n$-dodecyloxy and $n$-tetradecyloxy derivatives were measured by differential scanning calorimetry. Data are recorded in table 3. Enthalpy values of the nematic phase transitions agree well with the literature value (Marzotko and Demus 1975) which has helped in further confirmation of meso-

\begin{tabular}{|c|c|c|c|c|c|c|c|c|}
\hline \multirow{2}{*}{$\begin{array}{l}\text { Compound } \\
\text { no. }\end{array}$} & \multirow{2}{*}{$\begin{array}{c}R=-\mathrm{C}_{n} \mathrm{H}_{2 n+1} \mathrm{~F} \\
n=\end{array}$} & \multirow[b]{2}{*}{ Formula } & \multicolumn{3}{|c|}{ Required (\%) } & \multicolumn{3}{|c|}{ Found (\%) } \\
\hline & & & $\mathrm{C}$ & $\mathrm{H}$ & $\mathrm{N}$ & $\mathrm{C}$ & $\mathrm{H}$ & $\mathrm{N}$ \\
\hline 1 & 1 & $\mathrm{C}_{22} \mathrm{H}_{20} \mathrm{~N}_{2} \mathrm{O}_{5}$ & $68 \cdot 32$ & 4.95 & $6 \cdot 93$ & $68 \cdot 14$ & $5 \cdot 06$ & $6 \cdot 45$ \\
\hline 2 & 2 & $\mathrm{C}_{23} \mathrm{H}_{22} \mathrm{~N}_{2} \mathrm{O}_{5}$ & $68 \cdot 90$ & $5 \cdot 26$ & $6 \cdot 70$ & 68.66 & $5 \cdot 49$ & $6 \cdot 91$ \\
\hline 3 & 3 & $\mathrm{C}_{24} \mathrm{H}_{24} \mathrm{~N}_{2} \mathrm{O}_{5}$ & $69 \cdot 44$ & $5 \cdot 55$ & $6 \cdot 48$ & 69.83 & 5.78 & $6 \cdot 27$ \\
\hline 4 & 4 & $\mathrm{C}_{25} \mathrm{H}_{26} \mathrm{~N}_{2} \mathrm{O}_{5}$ & 69.95 & $5 \cdot 83$ & $6 \cdot 28$ & $70 \cdot 03$ & $5 \cdot 84$ & $5 \cdot 97$ \\
\hline 5 & 5 & $\mathrm{C}_{26} \mathrm{H}_{28} \mathrm{~N}_{2} \mathrm{O}_{5}$ & $70 \cdot 43$ & $6 \cdot 09$ & $6 \cdot 09$ & $70 \cdot 14$ & $6 \cdot 38$ & $6 \cdot 24$ \\
\hline 6 & 6 & $\mathrm{C}_{27} \mathrm{H}_{30} \mathrm{~N}_{2} \mathrm{O}_{5}$ & $70 \cdot 89$ & $6 \cdot 33$ & 5.91 & $70 \cdot 88$ & $6 \cdot 55$ & $5 \cdot 55$ \\
\hline 7 & 7 & $\mathrm{C}_{28} \mathrm{H}_{32} \mathrm{~N}_{2} \mathrm{O}_{5}$ & $71 \cdot 13$ & $6 \cdot 56$ & $5 \cdot 74$ & $71 \cdot 70$ & $6 \cdot 89$ & $5 \cdot 37$ \\
\hline 8 & 8 & $\mathrm{C}_{29} \mathrm{H}_{34} \mathrm{~N}_{2} \mathrm{O}_{5}$ & $71 \cdot 71$ & $6 \cdot 77$ & 5.58 & 71.64 & $6 \cdot 94$ & $5 \cdot 26$ \\
\hline 9 & 10 & $\mathrm{C}_{31} \mathrm{H}_{38} \mathrm{~N}_{2} \mathrm{O}_{5}$ & $72 \cdot 45$ & $7 \cdot 17$ & $5 \cdot 28$ & $72 \cdot 00$ & $7 \cdot 09$ & $5 \cdot 61$ \\
\hline 10 & 12 & $\mathrm{C}_{32} \mathrm{H}_{42} \mathrm{~N}_{2} \mathrm{O}_{5}$ & $73 \cdot 12$ & $7 \cdot 53$ & $5 \cdot 02$ & $73 \cdot 23$ & $7 \cdot 97$ & $4 \cdot 85$ \\
\hline 11 & 14 & $\mathrm{C}_{35} \mathrm{H}_{46} \mathrm{~N}_{2} \mathrm{O}_{5}$ & $73 \cdot 72$ & $7 \cdot 85$ & 4.78 & $73 \cdot 64$ & $7 \cdot 71$ & $4 \cdot 86$ \\
\hline 12 & 16 & $\mathrm{C}_{37} \mathrm{H}_{50} \mathrm{~N}_{2} \mathrm{O}_{5}$ & $74 \cdot 27$ & $8 \cdot 14$ & $4 \cdot 56$ & $74 \cdot 56$ & $7 \cdot 88$ & $4 \cdot 14$ \\
\hline
\end{tabular}
phase type.

Table 1. Elemental data of series I. 
3.1 Series I: 4-Methyl 2'-acetyloxy 4'-(4"-n-alkoxybenzoyloxy) azobenzenes

Twelve homologues have been synthesized. They are purely nematogenic. All the homologues of this series

Table 2. Transition temperatures $\left({ }^{\circ} \mathrm{C}\right)$ of the present series I.

\begin{tabular}{|c|c|c|c|c|}
\hline \multirow{2}{*}{$\begin{array}{l}\text { Compound } \\
\text { no. }\end{array}$} & \multirow{2}{*}{$\begin{array}{c}R=\mathrm{C}_{n} \mathrm{H}_{2 n+1} \\
n=\end{array}$} & \multicolumn{3}{|c|}{ Transition temperatures $\left({ }^{\circ} \mathrm{C}\right)$} \\
\hline & & $\mathrm{Cr}$ & $\mathrm{N}$ & I \\
\hline 1 & 1 & - $156 \cdot 0$ & $(\bullet 125 \cdot 0)$ & - \\
\hline 2 & 2 & - 148.0 & $(\bullet 129 \cdot 0)$ & - \\
\hline 3 & 3 & - 134.0 & $(\bullet 104 \cdot 0)$ & - \\
\hline 4 & 4 & - $128 \cdot 0$ & $(\bullet 119 \cdot 0)$ & $\bullet$ \\
\hline 5 & 5 & - $121 \cdot 0$ & $(\bullet 93 \cdot 0)$ & $\bullet$ \\
\hline 6 & 6 & - $148 \cdot 0$ & $(\bullet 103 \cdot 0)$ & $\bullet$ \\
\hline 7 & 7 & - 125.0 & $(\bullet 97 \cdot 0)$ & - \\
\hline 8 & 8 & - $102 \cdot 0$ & $(\bullet 94 \cdot 0)$ & - \\
\hline 9 & 10 & - $101 \cdot 0$ & $(\bullet 92 \cdot 5)$ & $\bullet$ \\
\hline 10 & 12 & - $87 \cdot 5$ & - $91 \cdot 0$ & $\bullet$ \\
\hline 11 & 14 & - $78 \cdot 0$ & $\bullet 90 \cdot 0$ & $\bullet$ \\
\hline 12 & 16 & - $104 \cdot 0$ & $(\bullet 87 \cdot 0)$ & $\bullet$ \\
\hline
\end{tabular}

() Monotropic value; $\mathrm{Cr}=$ crystalline phase; $\mathrm{N}=$ nematic phase; $\mathrm{I}=$ isotropic liquid phase.

Table 3. DSC data.

\begin{tabular}{lccc}
\hline $\begin{array}{l}\text { Compound no. } \\
\text { (table 1) }\end{array}$ & Transition & $\Delta{\mathrm{H} / \mathrm{Jg}^{-1}}$ & $\Delta \mathrm{S} \mathrm{Jg}^{-1} \mathrm{k}^{-1}$ \\
\hline 10 & $\mathrm{Cr}-\mathrm{N}$ & $45 \cdot 64$ & $0 \cdot 1274$ \\
& N-I & $00 \cdot 26$ & $0 \cdot 0007$ \\
11 & $\mathrm{Cr}-\mathrm{N}$ & $49 \cdot 38$ & $0 \cdot 1408$ \\
& N-I & $00 \cdot 33$ & $0 \cdot 0009$ \\
\hline
\end{tabular}

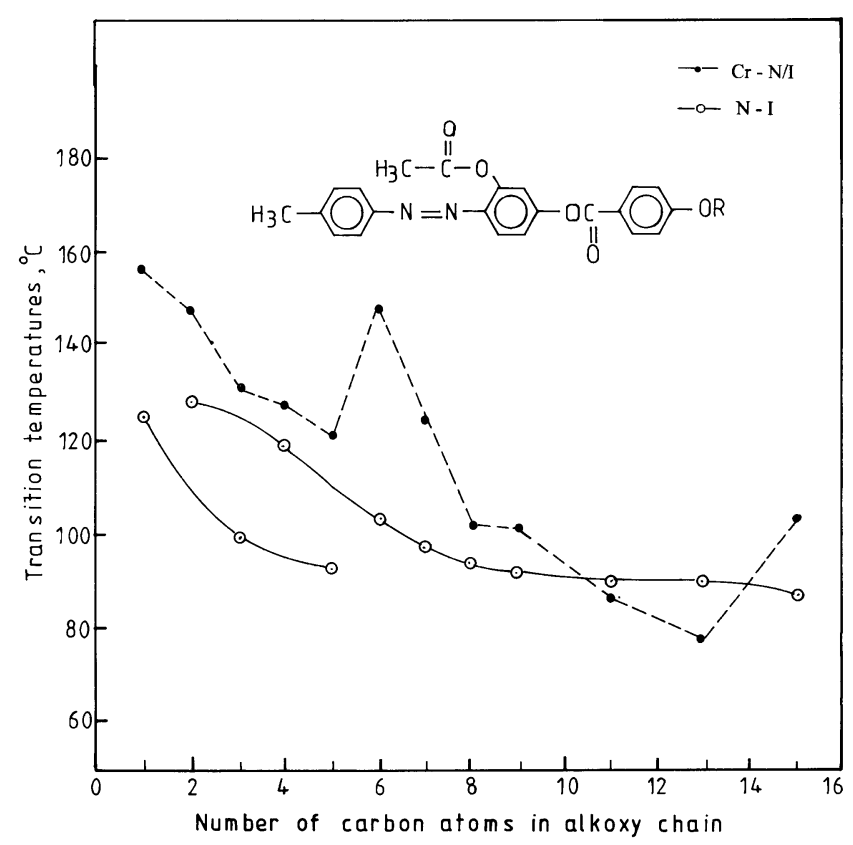

Figure 1. The phase behaviour of series I. exhibit monotropic nematic mesophase except the $n$ dodecyloxy- and $n$-tetradecyloxy homologues which are enantiotropic nematic.

It is clear from the plot of transition temperatures against the number of carbon atoms in the alkoxy chain (figure 1) that the nematic-isotropic transition temperatures exhibit the usual alternations associated with homologous series of mesomorphic ethers containing alkyl chain. Hence these transition points lie on two falling curves, the upper one determined by those ethers containing an even number of carbon atoms, and the lower by those with an odd number of carbons in the alkoxy chain. As a result of this alternation, the highest nematic-isotropic transition temperature found for ethyl ether is $129^{\circ} \mathrm{C}$.

Table 4 summarizes the average thermal stabilities and molecular structures of the present series I and the structurally related series A (Zaschke et al 1975), B and C (Vora et al 2001). The average nematic thermal stability of the present series I is lower than those of series A. Compared with the molecules of series A, the molecules of series I have increased breadth due to the lateral acetyloxy $\left(\mathrm{CH}_{3} \mathrm{COO}-\right)$ group on the central benzene ring. There are several reports in the literature (Gray 1966, 1976, 1979; Coates 1990; Demus and Hauser 1990) which

Table 4. Average thermal stabilities $\left({ }^{\circ} \mathrm{C}\right)$.

\begin{tabular}{lcccc}
\hline Series & I & A & B & C \\
\hline $\begin{array}{l}\text { SmC/N-I }\left(\mathrm{C}_{4}-\mathrm{C}_{8}\right) \\
\begin{array}{l}\text { Commencement } \\
\text { of smectic phase }\end{array}\end{array}$ & $101 \cdot 2$ & $227 \cdot 8$ & $233 \cdot 0$ & $39 \cdot 2$ \\
\hline
\end{tabular}<smiles>[R20]c1ccc(C(=O)Oc2ccc(N=Nc3ccc(C)cc3)c(OC(C)=O)c2)cc1</smiles><smiles>[R20]c1ccc(C(=O)Oc2ccc(N=Nc3ccc(C)cc3)cc2)cc1</smiles><smiles>[R6]Oc1ccc(C(=O)Oc2ccc(N=Nc3ccc(C)cc3)c(O)c2)cc1</smiles><smiles>[R20]c1ccc(C(=O)Oc2ccc(N=Nc3ccc(C)cc3)c(OC(=O)c3ccc([R20])cc3)c2)cc1</smiles>

Series C

Molecular structures of the compounds of series I, A, B and C. 
prove that the lateral substituents depress the thermal stabilities of the compounds, hence the average nematic thermal stability is lower in the present series I.

Reference to table 4 indicates that the average nematic thermal stability of series I is higher than that of series B. The molecules of series I and B differ only at lateral substituent. Series I has a lateral acetyloxy group whereas series B has a hydroxy group at that position. Due to the intramolecular association of lateral hydroxy group with an azo central linkage it is less effective in broadening of the molecules of series B whereas the effect of increase in breadth is prominent in series I because of the lateral acetyloxy group. Therefore, the average nematic thermal stability of series I is lower in the present series I.

Series C exhibits smectic C mesophase whereas series I exhibits only nematic mesophase. Hartung et al (1995) suggested packing of such molecules in series $\mathrm{C}$. The molecules are arranged in lamellar sheets which are characterized by a parallel molecular alignment with an interlocking of neighbouring molecules by their bulky branches and intercalation of the alkyl chains. However, the existence of a lateral motif in the present series I induces the nematic phase, preventing the more ordered in plane molecular association needed for smectic arrangement as observed in number of homologous series (Weissflog et al 1996). Hence the present series I exhibits only nematic mesophase.

\section{Conclusions}

New mesogenic homologous series with lateral acetyloxy group on central benzene nucleus were synthesized. The study indicated that the lateral acetyloxy group adversely affects the mesophase thermal stabilities. However, the short aliphatic chain can stabilize the nematic phase whereas long aromatic lateral substituents stabilize smectic phases.

\section{Acknowledgements}

The authors thank Prof. S G Shah, Dean, Faculty of Technology and Engineering, and Prof. Uma Chudasama,
Department of Applied Chemistry, MS University of Baroda, Vadodara, for providing research facilities.

\section{References}

Baumeister U, Kosturkiewicz Z, Hartung H, Weissflog W and Demus D 1990 Liq. Cryst. 7241

Berdague P, Perez F, Judeinstein P and Bayle J P 1995 New J. Chem. 19293

Coates D 1990 in Liquid crystals, applications and uses (ed.) B Bahadur (Singapore: World Scientific) Vol. 1, Ch. 3

Cox R, Volksen W and Dawson B L 1984 in Liquid crystals and ordered fluids (eds) A C Griffin and J F Johnson (New York: Plenum) Vol. 4, p. 33

Demus D and Hauser A 1990 in Selected topics in liquid crystal research (ed.) H D Koswig (Berlin: Akademie-Verlag) p. 19

Diele S, Madicke A, Knauft K, Neutzler J, Weissflog W and Demus D 1991 Liq. Cryst. 1047

Gallardo V and Muller H J 1984 Mol. Cryst. Liq. Cryst. 10213

Gray G W 1966 Mol. Cryst. 1333

Gray G W 1976 in Advances in liquid crystals (ed.) G H Brown (New York: Academic Press) Vol. 2, p. 1

Gray G W 1979 in The molecular physics of liquid crystals (eds) G R Luckhurst and G W Gray (London: Academic Press) Chs $1 \& 12$

Hartung H, Hofmann F, Stutzer C and Weissflog W 1995 Liq. Cryst. 19839

Marzotko D and Demus D 1975 Pramana - Suppl. 189

Perez F, Judeinstein P, Bayle J P, Roussel F and Fung B M 1997 Liq. Cryst. 22711

Vogel A I 1989 in Text book of practical organic chemistry (London: ELBS and Longmann) 5th ed. p. 946

Vora R A, Prajapati A K, Kevat J B and Raina K K 2001 Liq. Cryst. 28983

Weissflog W and Demus D 1983 Cryst. Res. Technol. 18 K21

Weissflog W and Demus D 1984 Cryst. Res. Technol. 1955

Weissflog W and Demus D 1985 Mater. Chem. Phys. 12461

Weissflog W and Demus D 1988 Liq. Cryst. 3275

Weissflog W and Jacobi A 1997 Mol. Cryst. Liq. Cryst. 30415

Weissflog W, Diele S, Pelzl G, Manke H and Demus D 1986 Liq. Cryst. 1101

Weissflog W, Demus D and Diele S 1990 Mol. Cryst. Liq. Cryst. 1919

Weissflog W, Wiegeleben A, Haddawi S and Demus D 1996 Mol. Cryst. Liq. Cryst. 28115

Zaschke H, Debacq J and Schubfrt H 1975 Z. Chem. 15100 